\title{
Alcohol intake aggravates adipose browning and muscle atrophy in cancer-associated cachexia
}

\author{
Bo Wang ${ }^{1,2, *}$, Faya Zhang ${ }^{3, *}$, Hui Zhang ${ }^{3}$, Zhixiu Wang ${ }^{2}$, Yan-Nan Ma2,5, Mei-Jun \\ Zhu ${ }^{3}$ and Min Du ${ }^{1,2}$ \\ ${ }^{1}$ Beijing Advanced Innovation Center for Food Nutrition and Human Health, Beijing 100094, P. R. China \\ ${ }^{2}$ Department of Animal Sciences, Washington State University, Pullman, WA 99164, USA \\ ${ }^{3}$ Department of Pharmaceutical Sciences, College of Pharmacy, Washington State University, Spokane, WA 99210, USA \\ ${ }^{4}$ School of Food Science, Washington State University, Pullman, WA 99164, USA \\ ${ }^{5}$ Department of Chemistry and Lifer Sciences, Gansu Normal University for Nationalities, Hezuo 747000, P. R. China \\ *These authors have contributed equally to this work \\ Correspondence to: Min Du, email: min.du@wsu.edu \\ Hui Zhang, email: hzhang@wsu.edu
}

Keywords: alcohol; cachexia; adipose browning; muscle atrophy; retinoic acid

Received: August 24, $2017 \quad$ Accepted: October 13,2017 Published: November 01, 2017

Copyright: Wang et al. This is an open-access article distributed under the terms of the Creative Commons Attribution License 3.0 (CC BY 3.0), which permits unrestricted use, distribution, and reproduction in any medium, provided the original author and source are credited.

\section{ABSTRACT}

Cancer is commonly associated with cachexia, a paraneoplastic syndrome characterized by body weight loss, muscle wasting, adipose tissue atrophy and inflammation. Chronic alcohol consumption increases the risk of multiple types of cancer, and enhances cancer-associated cachexia (CAC), but the underlying mechanisms remain poorly defined. To test, C57BL/6 mice were fed with $0 \%$ or $20 \%(w / v)$ alcohol for 3 months, then inoculated with B16BL6 melanoma cells subcutaneously in the right side of the hip and continued to feed with/without alcohol for 3 or 4 weeks. Alcohol intake upregulated ALDH1A1 expression and elevated retinoic acid (RA) content in inguinal white adipose tissue (iWAT), which led to enhanced iWAT browning and brown adipose tissue (BAT) activation, accelerating fat loss. Moreover, alcohol increased muscle loss through augmenting muscle protein degradation, cell apoptosis and inflammation. In addition, alcohol reduced satellite cell density and impaired myogenesis in skeletal muscle. Taken together, alcohol aggravates cancer-associated cachexia at least partially through elevating adipose browning and muscle atrophy.

\section{INTRODUCTION}

Cancer-associated cachexia (CAC) is a paraneoplastic syndrome characterized by body weight loss, muscle wasting, adipose tissue atrophy and inflammation [1-3]. Cachectic patients progressively loss muscle and fat mass [2], which is associated with increased mortality risk [4]. Up to now, CAC is regarded as a non-curable condition [5] and there are very limited options to slow down CAC [6]. Because cachectic patients have reduced food intake [6], nutritional supplementary therapy partially reverses the wasting associated with cachexia [5], but the effectiveness is limited, suggesting the existence of additional mechanisms besides nutrition which are responsible for CAC incidence.

Increased metabolic rate, which accelerates weight loss, is one of major causes of CAC [7]. Due to the uncoupling effect of uncoupling protein-1 (UCP-1) which dissipates cross-membrane electrical gradient as heat, white adipose tissue browning increases energy expenditure [8]. Brown adipose tissue (BAT) activation [9-11] and beige adipocyte formation $[3,12]$ in cancer patients and tumorbearing animal models increase energy consumption, which precedes adipose tissue and skeletal muscle atrophy [3]. 
According to NIH [13], in 2013, $86.8 \%$ of people aged 18 or older in the United States drank alcohol at some point in their life time. Alcoholics showed a significant increase in total cancer mortality in comparison with the general population [14]. Alcohol consumption is a known risking factor for cancers $[15,16]$. As estimated, 5.2\% of all male cancers and $1.7 \%$ of all female cancers are related to alcohol intake [17]. Alcohol is oxidized into acetaldehyde via alcohol dehydrogenase and alcoholinducible cytochrome P-4502E1 (CYP2E1), and further oxidized to acetate by aldehyde dehydrogenase [18]. Because acetaldehyde is highly reactive, it is toxic and carcinogenic [19], which binds to DNA and forms carcinogenic adducts. Acetaldehyde-derived DNA adducts such as $\mathrm{N}^{2}$-ethylidene-2'-deoxyguanosine ( $\mathrm{N}^{2}$-EtdG) block translesion DNA synthesis and induce mutations [20, 21]. Aldehydes also induces genomic instability [22]. Consistently, alcohol consumption increases the risk of colorectal cancer [23, 24].

Though the tumorigenic effects of alcohol have been well studied, its impacts on the metabolic state of cancer patients are far less defined. Chronic alcohol intake enhances the oxidative capacity of brown adipose tissue (BAT) [25-27]. In addition, we recently reported that alcohol consumption induces white adipose tissue browning and activates thermogenesis by elevating peripheral retinoic acid (RA) levels [28]. Due to the lower nutrient partitioning priority for adipose tissue and skeletal muscle, the increased energy demand from BAT and beige adipocytes induced by alcohol likely deprives nutrients available for muscle and adipose tissue of cancer patients, aggravating CAC. Using a mice model bearing melanoma tumors, the objective of this study was to analyze the impact of alcohol intake on browning of adipose tissues of tumor-bearing mice and its association with CAC.

\section{RESULTS}

\section{Alcohol intake increases body weight and tissue mass loss in tumor-bearing mice}

To explore the effects of chronic alcohol on CAC, C57BL/6 mice were fed with $0 \%$ or $20 \%(\mathrm{w} / \mathrm{v})$ alcohol for 3 months, then inoculated with B16BL6 melanoma cells and continued to feed with/without alcohol for 3 or 4 weeks. Regardless of alcohol treatments, tumor cell inoculation reduced body weight and induced the loss of fat and muscle mass. Compared to tumor-bearing mice without alcohol, the alcohol group had lower body weight (Figure 1A), in line with the reduced mass of inguinal white adipose tissue (iWAT), gonadal white adipose tissue (gWAT), and BAT (Figure 1B-1D). Due to the large variations in weight loss among mice inoculated with tumors, the weights of tibialis anterior muscle (TA), gastrocnemius muscle (GA) and vastus lateralis muscle (VA) between mice with/without alcohol did not reach significance (Figure 1E-1G). In addition, because 4 mice in the alcohol plus tumor group were euthanized/ died before the end of 4 weeks due to emaciation, their muscle tissues were not isolated and included in above calculation. GA muscle weight was linearly correlated to body weight ( $\left.p=0.01, \mathrm{R}^{2}=0.8\right)$; when the missing values were imputed using the regression equation, there was a significant reduction in GA muscle mass of alcohol treated tumor bearing mice (Figure $1 \mathrm{H}$ ).

\section{Alcohol intake enhances white adipose tissue browning in tumor-bearing mice}

Consistent with a previous study [3], iWAT adipocytes became smaller and multilocular after tumor implantation (Figure 2A-2B). More UCP1 positive beige adipocytes were observed in tumor implanted mice. In addition, alcohol consumption further increased the abundance of multilocular adipocytes in the tumor-bearing mice with smaller adipocyte sizes (Figure $2 \mathrm{~A}-2 \mathrm{C}$ ). The UCP1 content in iWAT was increased due to both tumor implantation and alcohol consumption (Figure 2D). Similarly, the lipid content in BAT of tumor-bearing mice was lower than control mice, which was further reduced due to alcohol intake (Figure 2E).

ALDH1A1 plays an important role in producing RA and inducing beige adipogenesis [28]. Mice implanted with tumor cells had higher ALDH1A1 protein contents (Figure 3A and 3B). Alcohol consumption increased ALDH1A1 protein levels in both control and tumor mice compared to their water-drinking counterparts (Figure 3A and $3 \mathrm{~B}$ ). Furthermore, we analyzed RA in iWAT and found that tumor mice had higher RA level in iWAT and alcohol consumption increased RA in both control and tumor mice (Figure 3C). Consequently, alcohol increased PR/ SET Domain 16 (PRDM16) and UCP1 protein contents in iWAT of tumor mice (Figure 3A and 3B). Similarly, alcohol increased the expression of Aldhlal and the browning related genes including $\operatorname{Prdm16}$, peroxisome proliferator-activated receptor gamma coactivator 1 alpha (Ppargcla), Ucp1, cell death-inducing DNA fragmentation factor, alpha subunit-like effector A (Cidea), elongation of very long chain fatty acids (FEN1/Elo2, SUR4/Elo3, yeast)-like 3 (Elovl3) and cytochrome c oxidase subunit VIIa 1 (Cox7a1) (Figure 3D). In addition, tumor mice had higher mRNA levels of brown adipose genes in BAT, which was further upregulated by alcohol (Figure 3E).

White adipose tissue browning leads to increased lipolysis. The protein levels of hormone sensitive lipase (HSL), phosphorylated HSL (Ser563) and adipose triglyceride lipase (ATGL) were higher in alcohol supplemented mice implanted with tumor (Figure 4A and 4B). In addition, chronic inflammation is known to increase UCP1 expression and browning of WAT in cancer mice [3] and lipolysis [29, 30]. We found that tumor implantation increased interleukin (IL) 6 expression 
in iWAT, while alcohol consumption increased IL18 expression in tumor-bearing mice (Figure 4C).

In summary, these data showed that tumor induced activation of BAT and browning of white adipose tissue, which increased lipolysis.

\section{Alcohol intake induces skeletal muscle protein degradation, apoptosis and inflammation}

WAT browning is an early event in the pathophysiology of CAC, preceding skeletal muscle loss [3]. Tumor implanted mice had smaller fibers in TA showing the occurrence of muscle atrophy, and alcohol consumption aggravated muscle atrophy in tumor mice (Figure 5A-5C). Cachexia is associated with degradation of actomyosin, actin and myosin [31]. Here we found tumor cell implantation increased the protein content of muscle atrophy F-box (MAFbx) (Figure 5D and 5E), a muscle specific E3-ubiquitin ligase, indicating increased protein degradation in skeletal muscle. Alcohol further increased MAFbx expression (Figure 5D and 5E), which would aggravate muscle loss in mice with tumors. On the contrary, alcohol consumption impaired AMPactivated protein kinase (AMPK) activation (Figure $5 \mathrm{~F}$ and $5 \mathrm{G}$ ), which was important for myogenesis and muscle regeneration [32-34]. Consistently, alcohol reduced the

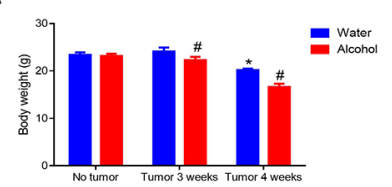

$\mathrm{E}$

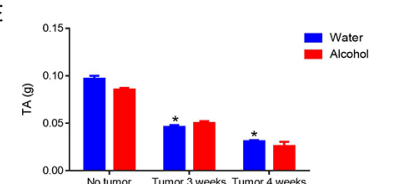

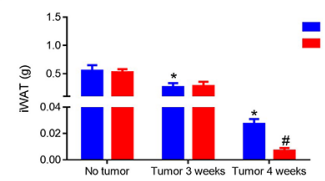

$\mathrm{F}$

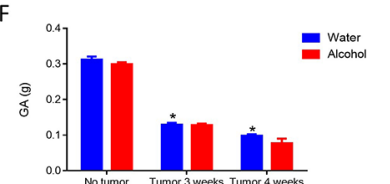

C

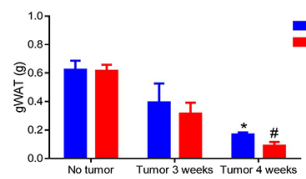

G

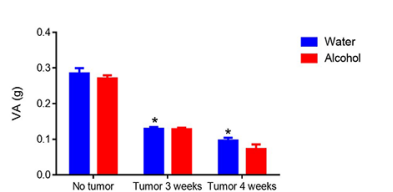

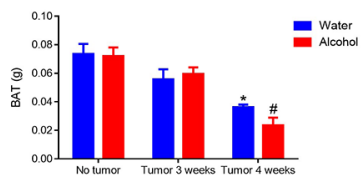

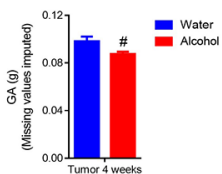

Figure 1: Alcohol increased body weight and tissue mass loss in mice implanted with tumor cells. C57BL6 mice were supplemented with 0 or $20 \%(\mathrm{w} / \mathrm{v})$ alcohol for 3 months, and then inoculated with B16BL6 melanoma cells for 3 or 4 weeks. (A) Body weight. (B) Inguinal white adipose tissue (iWAT) weight. (C) Gonadal white adipose tissue (gWAT) weight. (D) Brown adipose tissue (BAT) weight. (E) Tibialis anterior (TA) muscle weight. (F) Gastrocnemius (GA) muscle weight. (G) Vastus lateralis (VA) weight. (H) GA muscle weight after adding missing values of GA imputed according to its correlation with body weight. ("compare to the control mice, * compare to the mice fed with water, $p<0.05$, mean \pm SEM)

A

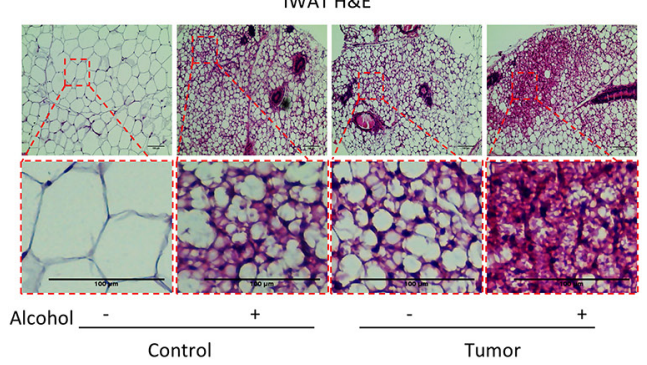

$\mathrm{D}$

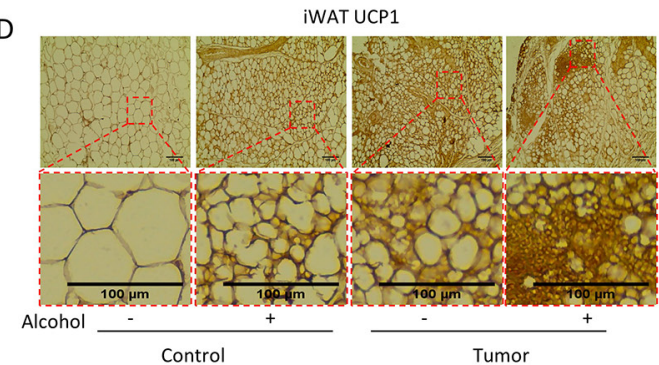

B

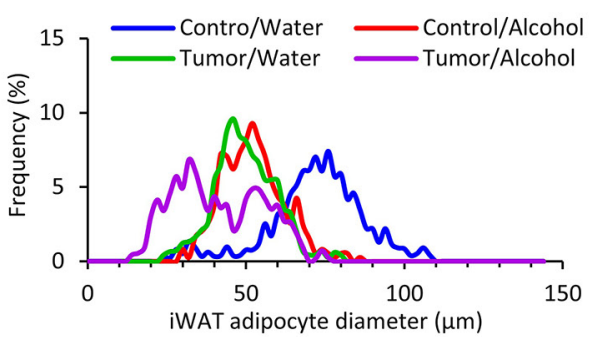

E

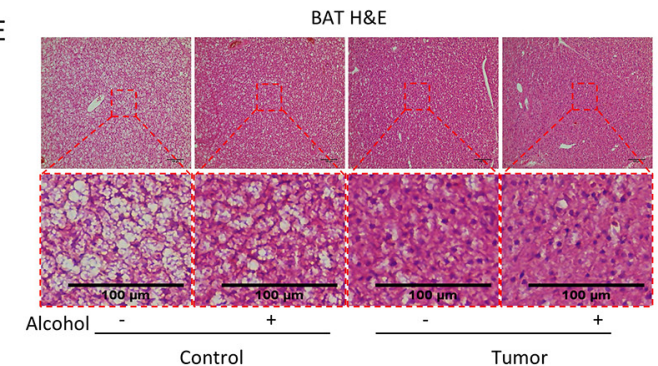

C

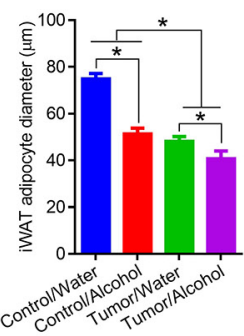

mor

Figure 2: Alcohol enhanced white adipose tissue browning in tumor mice. (A) Representative images of H\&E stained inguinal white adipose tissue (iWAT). (B) iWAT adipocytes size distribution. (C) Average iWAT adipocyte diameter. (D) Representative images of iWAT adipocytes stained with UCP1. (E) Representative images of H\&E stained BAT. Scale bar $=100 \mu \mathrm{m}$. 
expression of paired box 7 (Pax7) in GA muscle of tumor mice, indicating decreased satellite cell density; mRNA expression of myogenin (MyoG) was down-regulated in both control and tumor mice, suggesting impaired myogenesis and muscle protein synthesis (Figure $5 \mathrm{H}$ ). These data are consistent with earlier reports showing that alcohol consumption inhibits muscle protein synthesis [35-37].

In addition, alcohol reduced pro-caspase 1 but promoted caspase 1 activation in mice with tumors (Figure 6A and 6B). Activation of caspase-3 accelerates muscle proteolysis and loss $[5,38,39]$. Here we found
A

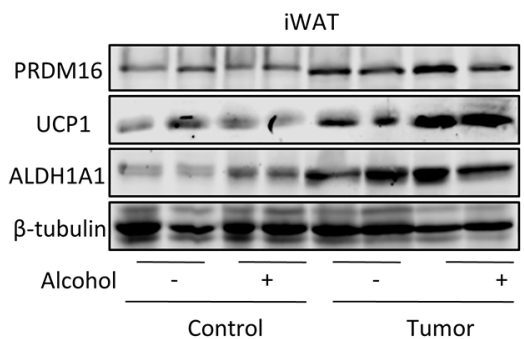

B

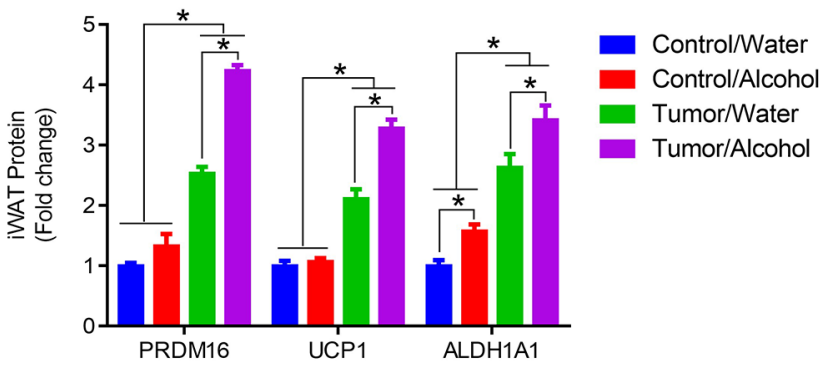

C

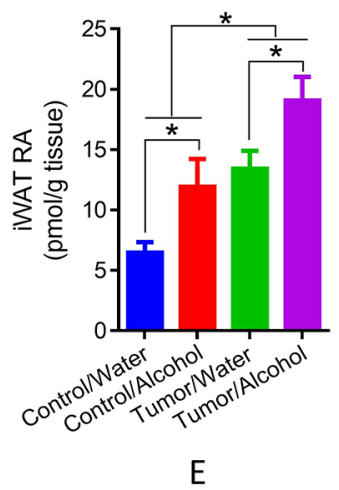

D

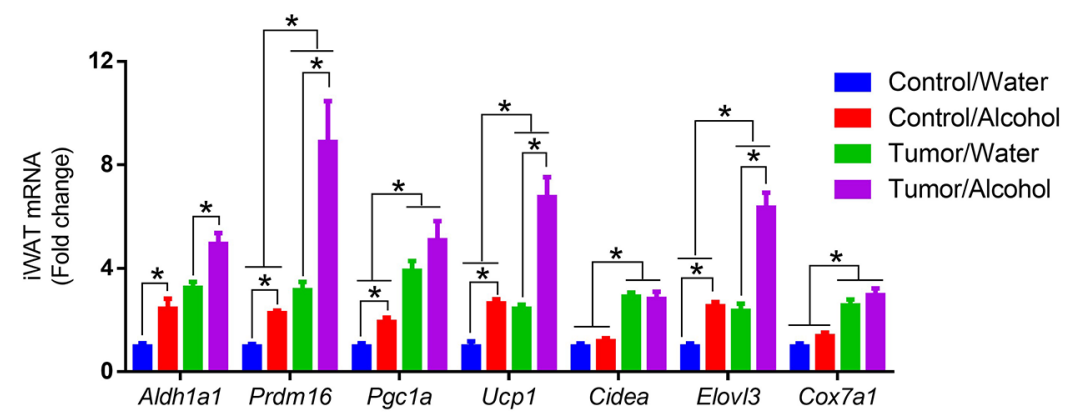

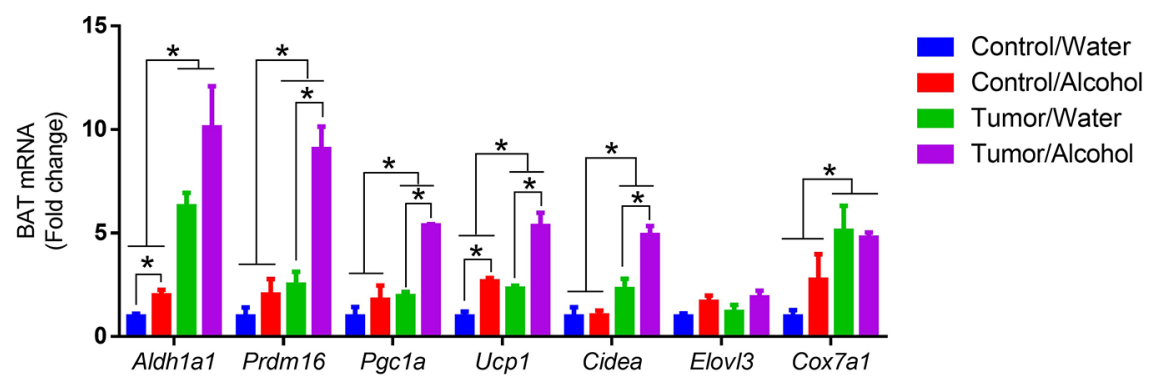

Figure 3: Alcohol and tumor inoculation upregulated brown/beige adipose genes. (A) Protein contents of PRDM16, ALDH1A1 and UCP1 in iWAT. (B) Quantification of protein contents. (C) RA contents in iWAT. (D) mRNA levels of Aldh1al, Prdm 16, Pgcla, Ucp1, Cidea, Elovl3 and Cox7al in iWAT. (E) mRNA levels of Aldh1a1, Prdm16, Pgcla, Ucp1, Cidea, Elovl3 and Cox7a1 in BAT. $\left({ }^{*} p<0.05\right.$, mean \pm SEM $)$.

A

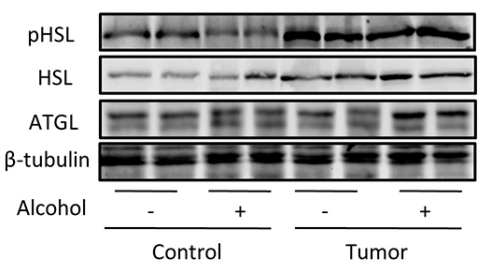

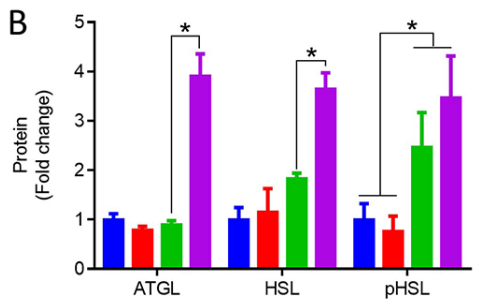

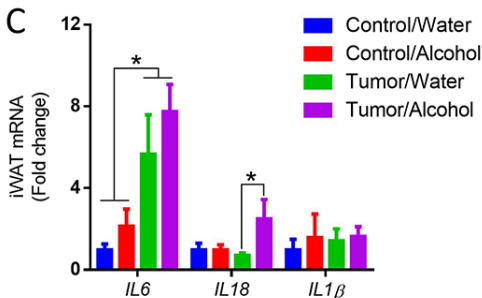

Figure 4: Alcohol increased lipolysis in inguinal white adipose tissue (iWAT) of tumor mice. (A) Protein contents of pHSL, HSL, and ATGL in iWAT. (B) Quantification of protein contents. (C) mRNA levels of $I L 6, I L 18$ and IL1 $\beta$ in iWAT. ( ${ }^{*} p<0.05$, mean \pm SEM). 
that alcohol increased pro-caspase 3 and activated caspase 3 in mice with tumors (Figure 6A and 6C). Alcohol reduced PYD-domains-containing protein 3 (NLRP3) in control mice but not in mice with tumors (Figure 6D and 6E). Moreover, alcohol increased IL-1 $\beta$ in control and tumor mice (Figure 6D and 6F). In summary, these data suggest that chronic alcohol consumption increases protein degradation, cell apoptosis and inflammation in the skeletal muscle of mice with tumors.

\section{DISCUSSION}

Alcohol and its metabolite, acetaldehyde, has long been recognized as carcinogens [15, 16, 19, 22]. However, the role of alcohol on energy homeostasis of cancer patients is poorly understood. In this study, we discovered that alcohol consumption aggravates cancer induced cachexia partially via inducing white adipose tissue browning. Our study revealed the relationship between alcohol and CAC which is significant for cancer treatment and patient care.
Alcohol and retinol (Vitamin A) share common metabolic enzymes involved in their conversion into aldehydes and acids [40]. We previously reported that alcohol consumption promotes adipose tissue browning by increasing the peripheral RA level in serum and adipose tissue [28]. In this study, we did not detect significant reduction in body weight and fat mass due to alcohol consumption in the absence of tumor, but reduction in body weight was observed in male mice due to alcohol consumption in our previous study [28]; the difference could be due to gender difference of mice and also the dose of alcohol used. In addition, we found that alcohol consumption upregulated ALDH1A1 which in turn elevated RA in adipose tissue. RA blocks white adipogenesis via inhibiting Zfp423 expression [41]; on the other hand, RA upregulates the expression of brown adipogenic genes, activates BAT and induces the formation of thermogenic beige adipocytes [28, 42-44]. While the thermogenic activity of brown and beige adipocytes increases energy expenditure which contributes to obesity prevention, it causes unfavorable consequences in cancer patients $[2,3,12]$; the elevated energy expenditure and
A

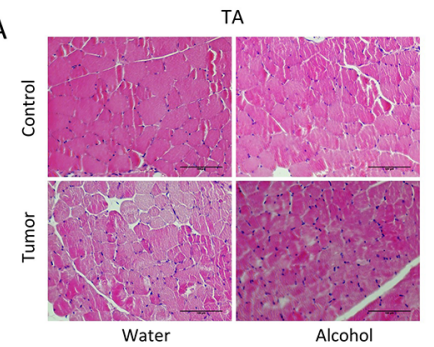

D

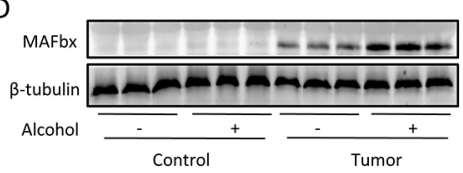

G

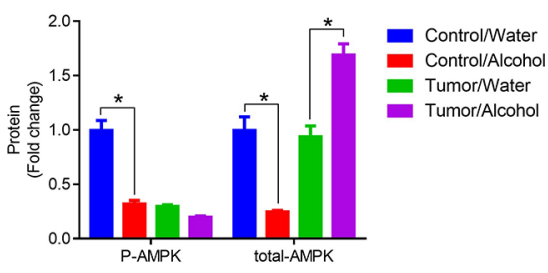

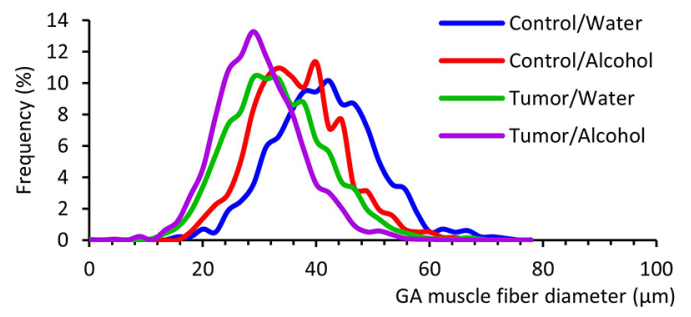

C

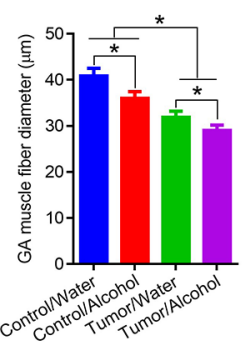

E

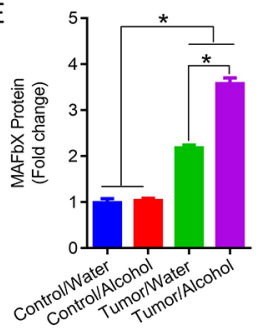

F

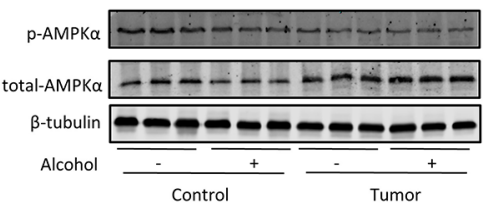

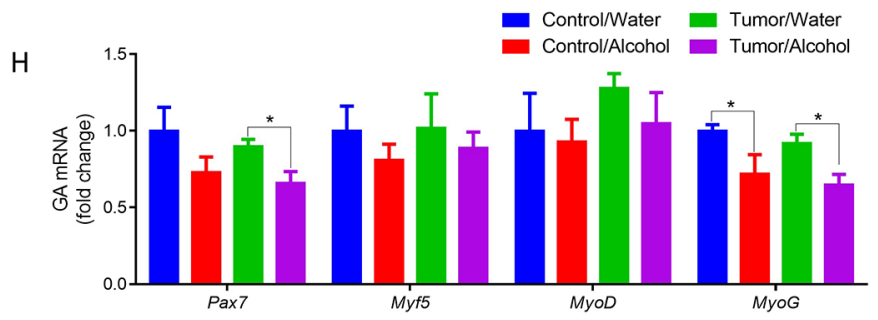

Figure 5: Alcohol promoted skeletal muscle atrophy in tumor mice. (A) Representative images of H\&E stained Tibialis anterior (TA) muscle, error bar $=100 \mu \mathrm{m}$. (B) Size distribution of TA muscle fibers. (C) Average diameter of TA muscle fibers. (D) Protein content of MAFbx in GA muscle. (E) Quantification of MAFbx protein content. (F) Protein content of pAMPK and total-AMPK in GA muscle. (G) Quantification of pAMPK and total-AMPK protein content. (H) mRNA levels of Pax 7, Myf5, MyoD and MyoG in GA muscle. $\left(^{*} p<\right.$ 0.05 , mean $\pm \mathrm{SEM})$. 
body weight loss increase mortality [45]. Currently, RA is commonly used in cancer prevention and treatment [46-48], and our data suggest the negative impact of RA treatment in dissipating energy needed for patients, especially those with late stage cancers.

WAT browning is an early event in the pathophysiology of CAC, preceding skeletal muscle loss [3]. In this study, mice implanted with tumor lose more than $90 \%$ WAT and more than $60 \%$ skeletal muscle in 4 weeks, with alcohol consumption further worsening muscle and fat loss. Alcohol is well known to inhibit muscle protein synthesis [35-37]. In the current study, at the molecular level, alcohol promoted muscle protein degradation, apoptosis and inflammation. Cancer cachexia is characterized by systemic inflammation. The elevated cytokines induce anorexia, upregulate expression of muscle
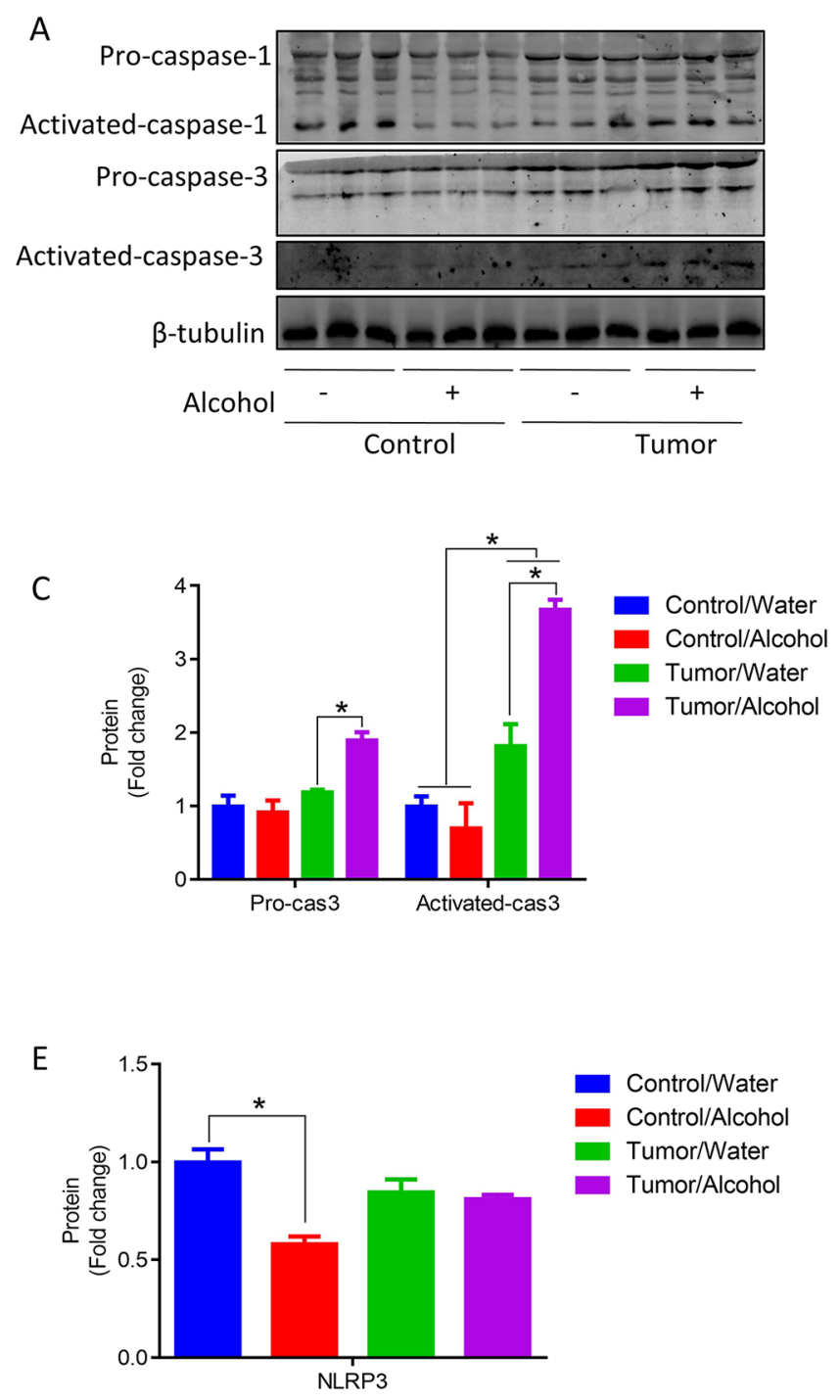

atrophy-associated genes and increase protein degradation $[2,5,49-51]$. Catabolism of muscle protein increases while anabolism of proteins decreases which result in net protein breakdown [5]. Consistently, alcohol consumption upregulated IL-1 $\beta$, a marker of inflammation; alcohol also activated Caspase-1 and Caspase-3, key mediators of cell apoptosis. In addition, alcohol consumption dramatically increased MAFbx, a muscle-specific E3 ubiquitin ligases that mediates muscle protein degradation [31, 52]. In addition, alcohol consumption reduced the satellite cell density and inhibited myogenesis, which impair muscle regeneration and lead to muscle loss.

Though CAC is known to reduce life quality and survival time, its treatment options are limited [53]. In addition to provide nutrients, therapies reducing energy expenditure may also be needed for effective CAC

B

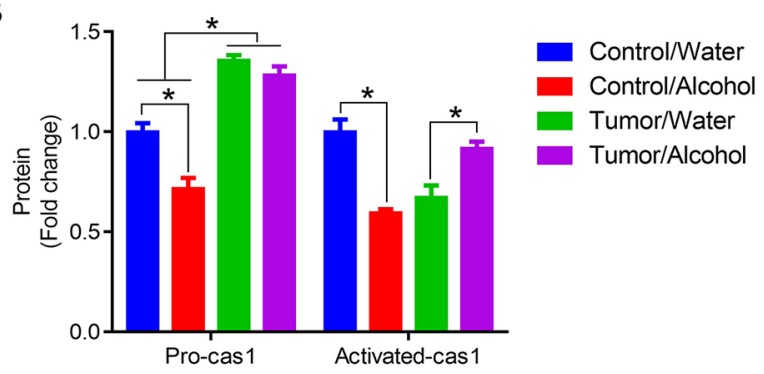

D

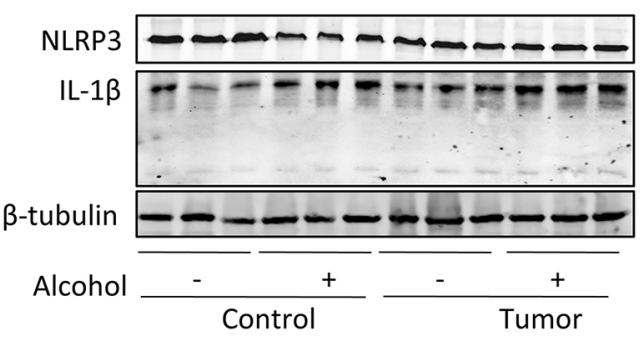

$\mathrm{F}$

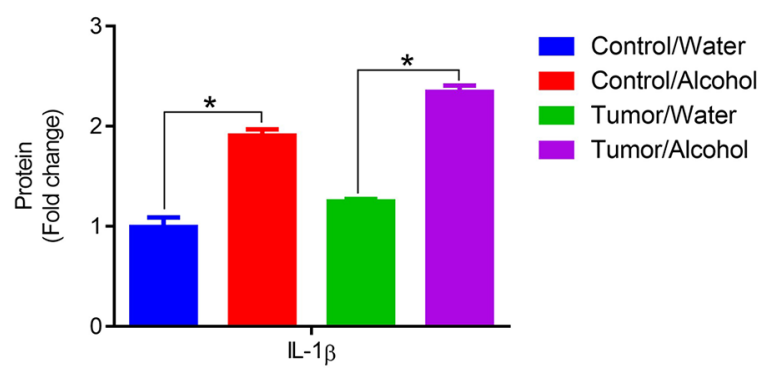

Figure 6: Alcohol promoted apoptosis and inflammation in skeletal muscle of tumor mice. (A-C) Pro-caspase 1, activated caspase 1, Pro-caspase 3 and activated caspase 3 protein contents in GA muscle. (D-F) NLRP3 and IL-1 $\beta$ protein contents in GA muscle. $\left({ }^{*} p<0.05\right.$, mean $\left.\pm \mathrm{SEM}\right)$. 
Table 1: qPCR primer sequences

\begin{tabular}{|c|c|c|c|c|}
\hline $\begin{array}{l}\text { Gene } \\
\text { name }\end{array}$ & Forward (5' to $\left.3^{\prime}\right)$ & Reverse (5' to 3') & $\begin{array}{l}\text { Product } \\
\text { size (bp) }\end{array}$ & $\begin{array}{c}\text { Accession } \\
\text { number }\end{array}$ \\
\hline Prdm 16 & CAGCACGGTGAAGCCATTC & GCGTGCATCCGCTTGTG & 87 & XM_006539178.3 \\
\hline Ucpl & ACTGCCACACCTCCAGTCATT & СTTTGCCTCACTCAGGATTGG & 123 & NM_009463.3 \\
\hline Pgcla & CCTCACACCAAACCCACAGA & CCTCATGCGGTCACTGTCG & 272 & XM_006503779.3 \\
\hline Cidea & ATCACAACTGGCCTGGTTACG & TACTACCCGGTGTCCATTTCT & 136 & NM_007702.2 \\
\hline Elovl3 & GATGGTTCTGGGCACCATCTT & CGTTGTTGTGTGGCATCCTT & 73 & XM_006526624.3 \\
\hline $\operatorname{Cox} 7 a 1$ & CAGCGTCATGGTCAGTCTGT & AGAAAACCGTGTGGCAGAGA & 112 & NM_009944.3 \\
\hline Aldhlal & CCTTGCATTGTGTTTGCAGATG & GCTCGCTCAACACTCCTTTTC & 158 & NM_013467.3 \\
\hline$I L-1 \beta$ & TCGCTCAGGGTCACAAGAAA & CATCAGAGGCAAGGAGGAAAAC & 73 & XM_006498795.3 \\
\hline$I L-18$ & ATGCTTTCTGGACTCCTGCCTGCT & GGCGGCTTTCTTTGTCCTGATGCT & 89 & XM_006510028.3 \\
\hline$I L-6$ & GAGGATACCACTCCCAACAGACC & AAGTGCATCATCGTTGTTCATACA & 141 & NM_001314054.1 \\
\hline $\operatorname{Pax} 7$ & TTGGGGAACACTCCGCTGTGC & CAGGGCTTGGGAAGGGTTGGC & 115 & XM_006538631.1 \\
\hline Myf5 & AAACTCCGGGAGCTCCGCCT & GGCAGCCGTCCGTCATGTCC & 125 & XM_006513319.2 \\
\hline MyoD & TCTGGAGCCCTCCTGGCACC & CGGGAAGGGGGAGAGTGGGG & 100 & NM_010866.2 \\
\hline MyoG & GAGATCCTGCGCAGCGCCAT & CCCCGCCTCTGTAGCGGAGA & 97 & NM_031189.2 \\
\hline 18 s rRNA & TTGTACACACCGCCCGTCGC & СTTCTCAGCGCTCCGCCAGG & 102 & NR_003278.3 \\
\hline
\end{tabular}

management. In agreement, in a mouse model, inhibition of catabolic lipase by genetic ablation of $\mathrm{Atgl}$ or $\mathrm{Hsl}$ ameliorates CAC [54]. Based on our discovery, to improve life quality and prolong survival time of cancer patients, alcohol consumption needs to be controlled in order to reduce energy dissipation.

\section{MATERIALS AND METHODS}

\section{Animal treatments and tumor cell inoculation}

Female C57BL/6 mice at 6 weeks of age were purchased from Charles River Laboratories (Wilmington, MA) and single housed in plastic cages with micro-filter tops in the SPBS Vivarium at WSU-Spokane, which is fully accredited by the Association for the Assessment and Accreditation of Laboratory Animal Care. Mice were allowed free access to Purina 5001 rodent laboratory chow and sterilized Milli-Q water. After one week of acclimation, mice were randomly divided into two groups. The control group was continuously provided with chow and Milli-Q water. The treatment group was provided with chow and $20 \%(\mathrm{w} / \mathrm{v})$ alcohol diluted from 190-proof Everclear (St. Louis, MO) with sterilized Milli-Q water. Similar doses of alcohol have been used in our previous studies $[28,45,55]$. After 3 months, mice in each group were further divided into two sub-groups with/without tumor inoculation. All studies were approved by the Institutional Animal Care and Use Committee at Washington State University.
For tumor inoculation, highly invasive and metastatic B16BL6 melanoma cell line originally obtained from the Mason Research Institute, Worcester, MA, was used. Tumor cells were cultured in Dulbecco's modified Eagles medium supplemented with 10\% FBS, $1 \%$ penicillin and streptomycin in a humidified incubator with $5 \% \mathrm{CO}_{2}$ at $37^{\circ} \mathrm{C}$. Cells were harvested when they reached $50-70 \%$ confluence. Each mouse was inoculated with $2 \times 10^{5}$ cells (in $200 \mu \mathrm{l}$ PBS) subcutaneously in the right side of the hip.

Animals were euthanized at 3 or 4 weeks after tumor inoculation. There were originally 10 mice for control and 4-weeks tumor groups. However, for the tumor inoculated mice consuming alcohol, four mice were euthanized/ died during the $4^{\text {th }}$ week due to emaciation. These mice were stored in $-20{ }^{\circ} \mathrm{C}$ before fat tissues were isolated and muscle tissues were not isolated. To balance, six samples from other three groups were randomly chosen for further biochemical analysis. Muscle tissues used for biochemical analysis were isolated at 4 weeks after tumor inoculation. Because of limited amount of fat tissues in mice inoculated with tumor for 4 weeks, fat tissues used for biochemical analysis were isolated at 3 weeks after tumor inoculation.

\section{Tissue processing and histological examination}

Adipose and muscle tissues were processed as previously described [42]. Briefly, tissues were fixed in 4\% paraformaldehyde for $12 \mathrm{~h}$ at $4{ }^{\circ} \mathrm{C}$, then paraffin embedded and sectioned. Following deparaffinization, tissue sections 
were used for H\&E staining or immunostaining. For immunostaining, sections were heated in citrate buffer for $20 \mathrm{~min}$, blocked with 5\% goat serum in TBS containing $0.3 \%$ Triton $\mathrm{X}-100$ for $2 \mathrm{~h}$, then incubated sequentially with primary antibodies overnight and secondary antibodies for $1 \mathrm{~h}$. Sections were then mounted in a BAPI mounting medium (Vector Lab, Burlingame, CA) and subjected to microscopic examination.

\section{Quantitative real-time PCR (qRT-PCR)}

Total RNA was isolated using TRIzol (Life technologies, Grand Island, NY), and cDNA was synthesized using iScript ${ }^{\mathrm{TM}}$ cDNA Synthesis Kit (Bio-Rad, Hercules, CA). qRT-PCR was performed using CFX RTPCR detection system (Bio-Rad) with SYBR green RTPCR kit from Bio-Rad (Hercules, CA). Primer sequences are listed in Table 1. All values were normalized to the level of a housekeeping gene: 18S rRNA.

\section{Immunoblotting analyses}

Immunoblotting analysis was performed as previously described [42] using an Odyssey Infrared Imaging System (LiCor Biosciences, Lincoln, NE). Density of bands was quantified and then normalized to the $\beta$-tubulin content.

\section{Antibodies and reagents}

Antibodies against $\beta$-tubulin (\#2146), IL$1 \beta$ (\#12242), caspase-1 (\#3866), cleaved caspase-1 (\#4199), caspase-3 (\#9662), cleaved caspase-3 (\#9661), HSL (\#4107), phospho-HSL (\#4139), ATGL (\#2138),

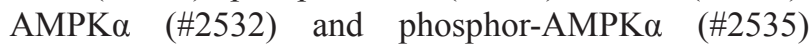
were purchased from Cell Signaling (Danvers, MA). Antibodies against UCP1 (Cat. No. PA1-24894) and PR/ SET Domain 16 (PRDM16) (\#PA5-20872) were bought from TheromoFisher Scientific (Waltham, MA). Antibody against PYD-domains-containing protein 3 (NLRP3) (\#PA1665) was purchased from Boster Biological Technology (Fremont, CA). Antibody against muscle atrophy F-box (MAFbx) (\#sc-33782) was purchased from Santa Cruz Biotechnology (Dallas, Texas). IRDye 800CW goat anti-rabbit and IRDye 680 goat anti-mouse secondary antibodies were bought from LI-COR Biosciences (Lincoln, NE).

\section{High performance liquid chromatography (HPLC) assay}

Toprevent isomerization and degradation of retinoids, serum samples were stored at $-80{ }^{\circ} \mathrm{C}$ and protected from light. RA was extracted according to a published protocol [56] and measured by HPLC [28] using a reverse phase column (Luna $3 \mu \mathrm{m} \mathrm{C18(2)} 100 \AA$, LC Column $150 \times 3 \mathrm{~mm})$. The mobile phase, methanol/
$\mathrm{H} 2 \mathrm{O}(65 / 35)$ was pumped at $1.0 \mathrm{~mL} / \mathrm{min}$. RA was detected by a Nexera X2 diode array detector at a wavelength of $340 \mathrm{~nm}$. RA standard was used for calculating standard curves and recovery rates, and the concentration of RA was expressed as $\mathrm{pmol} / \mathrm{mg}$ wet tissue weight.

\section{Statistical analysis}

All data are presented as means \pm standard errors of the mean (SEM). One-way ANOVA followed by a post hoc Tukey's test was used to compare differences among multiple groups. An unpaired, two-tail Student's t-test was used to compare differences between two groups. All analyses were performed using SAS 9.0 (SAS Institute Inc., Cary, NC). Statistical significance was assigned at $p<0.05$.

\section{Author contributions}

$\mathrm{BW}, \mathrm{HZ}$ and MD conceived the project; FYZ and $\mathrm{HZ}$ performed the animal treatments; BW, ZXW, YNM performed the sample analysis; MJZ assisted in HPLC analysis; BW and MD wrote the manuscript; HZ, FYZ and MJZ proofread the manuscript.

\section{CONFLICTS OF INTEREST}

The authors declare that there is no duality of interest associated with this manuscript.

\section{FUNDING}

The work was funded by NIH R15AA024284, R01HD067449 and R21AG049976, and the National Institute of Food and Agriculture, U.S. Department of Agriculture, under award number 2015-67015-23219. Bo Wang was supported by the China Scholarship Council's award (File No. 201206350033).

\section{REFERENCES}

1. Baracos VE. Cancer-associated cachexia and underlying biological mechanisms. Annu Rev Nutr. 2006; 26: 435-61. https://doi.org/10.1146/annurev.nutr.26.061505.111151.

2. Tisdale MJ. Cachexia in cancer patients. Nat Rev Cancer. 2002; 2: 862-71. https://doi.org/10.1038/nrc927.

3. Petruzzelli M, Schweiger M, Schreiber R, Campos-Olivas R, Tsoli M, Allen J, Swarbrick M, Rose-John S, Rincon M, Robertson G, Zechner R, Wagner EF. A switch from white to brown fat increases energy expenditure in cancerassociated cachexia. Cell Metab. 2014; 20: 433-47. https:// doi.org/10.1016/j.cmet.2014.06.011.

4. Anker SD, Negassa A, Coats AJ, Afzal R, Poole-Wilson PA, Cohn JN, Yusuf S. Prognostic importance of weight loss in chronic heart failure and the effect of treatment with angiotensin-converting-enzyme inhibitors: an observational 
study. Lancet. 2003; 361: 1077-83. https://doi.org/10.1016/ S0140-6736(03)12892-9.

5. Aoyagi T, Terracina KP, Raza A, Matsubara H, Takabe K. Cancer cachexia, mechanism and treatment. World J Gastrointest Oncol. 2015; 7: 17-29. https://doi.org/10.4251/ wjgo.v7.i4.17.

6. Fearon K, Arends J, Baracos V. Understanding the mechanisms and treatment options in cancer cachexia. Nat Rev Clin Oncol. 2013; 10: 90-9. https://doi.org/10.1038/ nrclinonc.2012.209.

7. Blum D, Omlin A, Baracos VE, Solheim TS, Tan BH, Stone P, Kaasa S, Fearon K, Strasser F; European Palliative Care Research Collaborative. Cancer cachexia: a systematic literature review of items and domains associated with involuntary weight loss in cancer. Crit Rev Oncol Hematol. 2011; 80: 114-44. https://doi.org/10.1016/j. critrevonc.2010.10.004.

8. Peschechera A, Eckel J. "Browning" of adipose tissue-regulation and therapeutic perspectives. Arch Physiol Biochem. 2013; 119: 151-60. https://doi.org/10.3109/1381 3455.2013.796995

9. Tsoli M, Moore M, Burg D, Painter A, Taylor R, Lockie SH, Turner N, Warren A, Cooney G, Oldfield B, Clarke S, Robertson G. Activation of thermogenesis in brown adipose tissue and dysregulated lipid metabolism associated with cancer cachexia in mice. Cancer Res. 2012; 72: 4372-82. https://doi.org/10.1158/0008-5472.CAN-11-3536.

10. Bing C, Brown M, King P, Collins P, Tisdale MJ, Williams G. Increased gene expression of brown fat uncoupling protein (UCP) 1 and skeletal muscle UCP2 and UCP3 in MAC16-induced cancer cachexia. Cancer Res. 2000; 60: 2405-10.

11. Shellock FG, Riedinger MS, Fishbein MC. Brown adipose tissue in cancer patients: possible cause of cancer-induced cachexia. J Cancer Res Clin Oncol. 1986; 111: 82-5.

12. Kir S, White JP, Kleiner S, Kazak L, Cohen P, Baracos VE, Spiegelman BM. Tumour-derived PTH-related protein triggers adipose tissue browning and cancer cachexia. Nature. 2014; 513: 100-4. https://doi.org/10.1038/ nature13528.

13. Alcoholism National Institute of Alcohol Abuse and Alcoholism. Alcohol Facts and Statistics. 2017.

14. Saieva C, Bardazzi G, Masala G, Quartini A, Ceroti M, Iozzi A, Gelain E, Querci A, Allamani A, Palli D. General and cancer mortality in a large cohort of Italian alcoholics. Alcohol Clin Exp Res. 2012; 36: 342-50. https://doi. org/10.1111/j.1530-0277.2011.01626.x.

15. Boffetta P, Hashibe M. Alcohol and cancer. Lancet Oncol. 2006; 7: 149-56. https://doi.org/10.1016/ S1470-2045(06)70577-0.

16. Rehm J, Baliunas D, Borges GL, Graham K, Irving H, Kehoe T, Parry CD, Patra J, Popova S, Poznyak V. The relation between different dimensions of alcohol consumption and burden of disease: an overview. Addiction. 2010; 105: 817-43.

17. Haas SL, Ye W, Lohr JM. Alcohol consumption and digestive tract cancer. Curr Opin Clin Nutr Metab Care. 2012; 15: 457-67. https://doi.org/10.1097/ MCO.0b013e3283566699.

18. Yin SJ. Alcohol dehydrogenase: enzymology and metabolism. Alcohol Alcohol Suppl. 1994; 2: 113-9.

19. Das SK, Vasudevan DM. Alcohol-induced oxidative stress. Life Sci. 2007; 81: 177-87. https://doi.org/10.1016/j. lfs.2007.05.005.

20. Singh R, Sandhu J, Kaur B, Juren T, Steward WP, Segerback D, Farmer PB. Evaluation of the DNA damaging potential of cannabis cigarette smoke by the determination of acetaldehyde derived N2-ethyl-2'-deoxyguanosine adducts. Chem Res Toxicol. 2009; 22: 1181-8.

21. Yu HS, Oyama T, Isse $T$, Kitagawa $K$, Tanaka M, Kawamoto T. Formation of acetaldehyde-derived DNA adducts due to alcohol exposure. ChemBiol Interact. 2010; 188: 367-75.

22. Tan SLW, Chadha S, Liu Y, Gabasova E, Perera D, Ahmed $\mathrm{K}$, Constantinou S, Renaudin X, Lee M, Aebersold $\mathrm{R}$, Venkitaraman AR. A class of environmental and endogenous toxins induces BRCA2 haploinsufficiency and genome instability. Cell. 2017; 169: $1105-18$ e15. https:// doi.org/10.1016/j.cell.2017.05.010.

23. Zhu JZ, Wang YM, Zhou QY, Zhu KF, Yu CH, Li YM. Systematic review with meta-analysis: alcohol consumption and the risk of colorectal adenoma. Aliment Pharmacol Ther. 2014; 40: 325-37. https://doi.org/10.1111/apt.12841.

24. Ratna A, Mandrekar P. Alcohol and cancer: mechanisms and therapies. Biomolecules. 2017. https://doi.org/10.3390/ biom7030061.

25. Huttunen P, Kortelainen ML, Hirvonen J. Foetal and lactational exposure to alcohol increases oxidative capacity of brown adipose tissue in the rat. A possible relationship to cot death. Br J Exp Pathol. 1989; 70: 691-5.

26. Huttunen P, Kortelainen ML. Chronic alcohol intake induces the oxidative capacity of brown adipose tissue in the rat. Pharmacol Biochem Behav. 1988; 29: 53-7.

27. Huttunen $P$, Kortelainen ML. Long-term alcohol consumption and brown adipose tissue in man. Eur J Appl Physiol Occup Physiol. 1990; 60: 418-24.

28. Wang B, Wang Z, de Avila JM, Zhu MJ, Zhang F, Gomez NA, Zhao L, Tian Q, Zhao J, Maricelli J, Zhang H, Rodgers $\mathrm{BD}, \mathrm{Du} \mathrm{M}$. Moderate alcohol intake induces thermogenic brown/beige adipocyte formation via elevating retinoic acid signaling. FASEB J. 2017. https://doi.org/10.1096/ fj.201700396R.

29. Plomgaard P, Fischer CP, Ibfelt T, Pedersen BK, van Hall G. Tumor necrosis factor-alpha modulates human in vivo lipolysis. J Clin Endocrinol Metab. 2008; 93: 543-9. https:// doi.org/10.1210/jc.2007-1761. 
30. Schreiber R, Zechner R. Lipolysis meets inflammation: arachidonic acid mobilization from fat. J Lipid Res. 2014; 55: 2447-9. https://doi.org/10.1194/jlr.C055673.

31. Acharyya S, Ladner KJ, Nelsen LL, Damrauer J, Reiser PJ, Swoap S, Guttridge DC. Cancer cachexia is regulated by selective targeting of skeletal muscle gene products. J Clin Invest. 2004; 114: 370-8.

32. Fu X, Zhu MJ, Dodson MV, Du M. AMP-activated protein kinase stimulates Warburg-like glycolysis and activation of satellite cells during muscle regeneration. J Biol Chem. 2015; 290: 26445-56. https://doi.org/10.1074/jbc. M115.665232.

33. Fu X, Zhu M, Zhang S, Foretz M, Viollet B, Du M. Obesity impairs skeletal muscle regeneration via inhibition of AMPactivated protein kinase. Diabetes. 2015.

34. Fu X, Zhao JX, Zhu MJ, Foretz M, Viollet B, Dodson MV, Du M. AMP-activated protein kinase $\alpha 1$ but not $\alpha 2$ catalytic subunit potentiates myogenin expression and myogenesis. Mol Cell Biol. 2013; 33: 4517-25.

35. Lang CH, Frost RA, Kumar V, Wu D, Vary TC. Impaired protein synthesis induced by acute alcohol intoxication is associated with changes in eIF4E in muscle and eIF2B in liver. Alcohol Clin Exp Res. 2000; 24: 322-31.

36. Vary TC, Lang $\mathrm{CH}$. Assessing effects of alcohol consumption on protein synthesis in striated muscles. Methods Mol Biol. 2008; 447: 343-55. https://doi. org/10.1007/978-1-59745-242-7_22.

37. Hong-Brown LQ, Frost RA, Lang CH. Alcohol impairs protein synthesis and degradation in cultured skeletal muscle cells. Alcohol Clin Exp Res. 2001; 25: 1373-82.

38. Du J, Wang X, Miereles C, Bailey JL, Debigare R, Zheng B, Price SR, Mitch WE. Activation of caspase-3 is an initial step triggering accelerated muscle proteolysis in catabolic conditions. J Clin Invest. 2004; 113: 115-23.

39. Pruznak AM, Kazi AA, Frost RA, Vary TC, Lang $\mathrm{CH}$. Activation of AMP-activated protein kinase by 5-aminoimidazole-4-carboxamide-1-beta-D-ribonucleoside prevents leucine-stimulated protein synthesis in rat skeletal muscle. J Nutr. 2008; 138: 1887-94.

40. Clugston RD, Blaner WS. The adverse effects of alcohol on vitamin A metabolism. Nutrients. 2012; 4: 356-71. https:// doi.org/10.3390/nu4050356.

41. Wang B, Fu X, Zhu MJ, Du M. Retinoic acid inhibits white adipogenesis by disrupting GADD45A-mediated Zfp423 DNA demethylation. J Mol Cell Biol. 2017. https://doi. org/10.1093/jmcb/mjx026.

42. Wang B, Fu X, Liang X, Wang Z, Yang Q, Zou T, Nie W, Zhao J, Gao P, Zhu MJ, de Avila JM, Maricelli J, Rodgers $\mathrm{BD}$, et al. Maternal retinoids increase PDGFRalpha+ progenitor population and beige adipogenesis in progeny by stimulating vascular development. EBioMedicine. 2017; 18: 288-99. https://doi.org/10.1016/j.ebiom.2017.03.041.

43. Puigserver P, Vazquez F, Bonet ML, Pico C, Palou A. In vitro and in vivo induction of brown adipocyte uncoupling protein (thermogenin) by retinoic acid. Biochem J. 1996; 317: 827-33.

44. Mercader J, Ribot J, Murano I, Felipe F, Cinti S, Bonet ML, Palou A. Remodeling of white adipose tissue after retinoic acid administration in mice. Endocrinology. 2006; 147: 5325-32. https://doi.org/10.1210/en.2006-0760.

45. Zhang F, Zhu Z, Meadows GG, Zhang H. Chronic alcohol consumption inhibits melanoma growth but decreases the survival of mice immunized with tumor cell lysate and boosted with alpha-galactosylceramide. Int Immunopharmacol. 2015; 28: 359-68. https://doi. org/10.1016/j.intimp.2015.06.018.

46. Altucci L, Gronemeyer H. The promise of retinoids to fight against cancer. Nat Rev Cancer. 2001; 1: 181-93. https://doi. org/10.1038/35106036.

47. Bertram JS, Vine AL. Cancer prevention by retinoids and carotenoids: independent action on a common target. Biochim Biophys Acta. 2005; 1740: 170-8. https://doi. org/10.1016/j.bbadis.2005.01.003.

48. Chen MC, Hsu SL, Lin H, Yang TY. Retinoic acid and cancer treatment. Biomedicine (Taipei). 2014; 4: 22. https:// doi.org/10.7603/s40681-014-0022-1.

49. Tijerina AJ. The biochemical basis of metabolism in cancer cachexia. Dimens Crit Care Nurs. 2004; 23: 237-43.

50. Evans WJ. Skeletal muscle loss: cachexia, sarcopenia, and inactivity. Am J Clin Nutr. 2010; 91: 1123S-7S. https://doi. org/10.3945/ajen.2010.28608A.

51. Braun TP, Zhu X, Szumowski M, Scott GD, Grossberg AJ, Levasseur PR, Graham K, Khan S, Damaraju S, Colmers WF. Central nervous system inflammation induces muscle atrophy via activation of the hypothalamic-pituitaryadrenal axis. J Exp Med. 2011; 208: 2449-63.

52. Lecker SH, Jagoe RT, Gilbert A, Gomes M, Baracos V, Bailey J, Price SR, Mitch WE, Goldberg AL. Multiple types of skeletal muscle atrophy involve a common program of changes in gene expression. FASEB J. 2004; 18: 39-51. https://doi.org/10.1096/fj.03-0610com.

53. von Haehling S, Anker SD. Cachexia as a major underestimated and unmet medical need: facts and numbers. J Cachexia Sarcopenia Muscle. 2010; 1: 1-5.

54. Das SK, Eder S, Schauer S, Diwoky C, Temmel H, Guertl B, Gorkiewicz G, Tamilarasan KP, Kumari P, Trauner M, Zimmermann R, Vesely P, Haemmerle G, et al. Adipose triglyceride lipase contributes to cancer-associated cachexia. Science. 2011; 333: 233-8. https://doi.org/10.1126/ science. 1198973.

55. Meadows GG, Blank SE, Duncan DD. Influence of ethanol consumption on natural killer cell activity in mice. Alcohol Clin Exp Res. 1989; 13: 476-9.

56. Kim YK, Quadro L. Reverse-phase high-performance liquid chromatography (HPLC) analysis of retinol and retinyl esters in mouse serum and tissues. Methods Mol Biol. 2010; 652: 263-75. https://doi. org/10.1007/978-1-60327-325-1_15. 